\title{
RESPONSABILIDADE SOCIAL EM UMA EMPRESA DISTRIBUIDORA DE ENERGIA ELÉTRICA
}

\section{SOCIAL RESPONSIBILITY IN A COMPANY DISTRIBUTION OF ELECTRICITY}

\author{
Data de submissão: 03-12-2014 \\ Aceite: 10-08-2015 \\ Rodrigo Camillo ${ }^{1}$ \\ Bruno José Ely ${ }^{2}$ \\ Flaviani Souto Bolzan Medeiros ${ }^{3}$ \\ Daiane Antonini Bortoluzzi ${ }^{4}$ \\ Lucélia da Silva Waechter ${ }^{5}$ \\ Sandra Leonara Obregon ${ }^{6}$
}

\begin{abstract}
RESUMO
No contexto de mudanças sociais, econômicas e tecnológicas, oriundo de guerras, desigualdades, avanços tecnológicos e escassez de matéria-prima, constata-se uma grande preocupação em estabelecer princípios éticos que levem à realização de ações de responsabilidade social nas organizações. Nesse sentido, o presente artigo tem como objetivo propor ações de melhoria no Programa de Responsabilidade Social, com base no Instituto Ethos, de uma distribuidora de energia elétrica. Para isso, quanto aos procedimentos metodológicos, o estudo caracteriza-se como qualitativo, do tipo descritivo, sendo desenvolvido por meio de entrevistas semiestruturadas com sete colaboradores da empresa. Dentre os resultados obtidos, foi possível verificar que os colaboradores têm consciência do papel que a referida empresa de energia vem desenvolvendo na busca contínua de qualidade, demonstrando informalmente certo grau de satisfação quanto à empresa. Ao mesmo tempo, percebeu-se, contudo, certo desconhecimento por parte dos colaboradores quanto ao trabalho que hoje é desenvolvido pela empresa, indicando a estagnação de informações.
\end{abstract}

Palavras-chave: responsabilidade social; responsabilidade social empresarial, Instituto Ethos.

\footnotetext{
${ }^{1}$ Possui graduação em administração de empresas pela Pontifícia Universidade Católica do Rio Grande do Sul - PUCRS. Porto Alegre. Rio Grande do Sul. Brasil. E-mail: rcamillo22@yahoo.com.br

2Possui graduação em Filosofia pela Universidade Federal do Rio Grande do Sul - UFRGS, graduação em Administração Pública pela Universidade Federal do Rio Grande do Sul - UFRGS, graduação em Administração de Empresas pela Universidade Federal do Rio Grande do Sul - UFRGS, mestrado em Administração pela Universidade Federal do Rio Grande do Sul - UFRGS e doutorado em Comunicação Social pela Pontifícia Universidade Católica do Rio Grande do Sul - PUCRS. Atualmente é professor da Pontifícia Universidade Católica do Rio Grande do Sul. Porto Alegre. Rio Grande do Sul. Brasil. E-mail: brunely@pucrs.br

${ }^{3}$ Possui graduação em Administração de Empresas pelo Centro Universitário Franciscano - UNIFRA, graduação em andamento em Formação de Professores para Educação Profissional pela Universidade Federal de Santa Maria - UFSM e mestrado em Engenharia de Produção pela Universidade Federal de Santa Maria - UFSM. Atualmente, é professora substituta na Unidade Descentralizada de Educação Superior da UFSM em Silveira Martins. Silveira Martins. Rio Grande do Sul. Brasil. E-mail: flaviani.13@gmail.com

${ }^{4}$ Possui graduação em Administração pelo Centro Universitário Franciscano - UNIFRA e mestrado em andamento em Administração pela Universidade Federal de Santa Catarina - UFSC. Florianópolis. Santa Catarina. Brasil. E-mail: daianeantonini@gmail. com

${ }^{5}$ Possui graduação em Administração pelo Centro Universitário Franciscano - UNIFRA. Atualmente é professora substituta no Instituto Federal de educação, ciência e tecnologia do Rio Grande do Sul- Câmpus Caxias do Sul. Caxias do Sul. Rio Grande do Sul. Brasil. E-mail: luwaechter@hotmail.com

${ }^{6}$ Possui graduação em andamento em Administração pelo Centro Universitário Franciscano - UNIFRA. Santa Maria. Rio Grande do Sul. Brasil. E-mail: sandraobregon12@gmail.com
} 


\begin{abstract}
In the context of social, economic and technological changes through which pass the countries and organizations, these transformations arising from wars, inequality, technological advances and shortage of raw materials, there has been a major concern in establishing ethical principles that lead to realization of shares social responsibility in organizations. In this sense, the present article aims to propose actions to improve the Social Responsibility Programme, based on the Ethos Institute in an electricity distributor. For this, the methodological procedures, the study is characterized as qualitative, descriptive type, being developed through semi-structured interviews with seven employees of the company. Among the results was possible to verify that employees are aware of the role that energy company has been developing for the continuous pursuit of quality, informally demonstrating a certain degree of satisfaction with the company. At the same time, research shows some ignorance on the part of employees about the work that is now developed by the company, thus directing to stagnation of information.
\end{abstract}

Keywords: social responsibility; corporate social responsibility, Ethos Institute.

\title{
1 INTRODUÇÃO
}

A situação atual em que se encontram o meio ambiente e todos os recursos naturais existentes no planeta instiga nos consumidores uma visão cada vez mais crítica a esse respeito. Os consumidores estão adotando uma postura de cobrança quanto à ética e o respeito ao meio ambiente na fabricação e geração de produtos e serviços pelas empresas.

Sustentabilidade e autodesenvolvimento deixaram de serem palavras desconhecidas dos cidadãos brasileiros e estão passando a fazer parte de suas rotinas. Nesse contexto, as empresas são cobradas pela situação atual do planeta e investem neste segmento, dando origem a novas práticas de sustentabilidade a todo o momento.

Aos poucos, percebe-se que a Responsabilidade Social Empresarial (RSE) tornou-se um fator de competitividade para os negócios e um diferencial para atrair novos investidores. No passado, o que identificava uma empresa competitiva era basicamente o preço de seus produtos e, após, a qualidade. Hoje, nota-se uma demanda para que as empresas invistam no permanente aperfeiçoamento de suas relações com todos os públicos, sejam clientes, fornecedores, empregados, parceiros, colaboradores ou comunidade.

Esses atos socialmente responsáveis deveriam ser encarados como uma postura sistemática para enraizar valores como a solidariedade no meio social, e não como forma de competitividade ou diferenciação organizacional apenas. A responsabilidade social empresarial não se restringe, assim, somente a grandes organizações que geram bons lucros e que têm centenas de colaboradores em seu quadro pessoal, mas também a médias, pequenas e micro empresas, pois suas diretrizes são baseadas em valores humanos.

Sendo um grande fator de competitividade e diferenciação em relação aos concorrentes, bem como uma forma de atrair novos investidores, a distribuidora de energia elétrica analisada neste estudo adota, desde 2001, algumas práticas de responsabilidade social e gestão ambiental. Dentre elas, estão a reciclagem e o reaproveitamento do lixo gerado na empresa; os projetos de reflorestamento e de arborização urbana; o programa de desenvolvimento do Código de Ética; as gestões de excelência empresarial (certificações ISO); as publicações anuais do Balanço Social da empresa; e o financiamento de diversos projetos ligados à área da cultura e do cinema no estado do Rio Grande do Sul.

Desse modo, o objetivo deste artigo é propor ações de melhoria no Programa de Responsabilidade Social, com base no Instituto Ethos, em uma distribuidora de energia elétrica localizada no Rio Grande do Sul que atua há dezoito anos no setor e atende $51 \%$ dos municípios do estado. Tal 
distribuidora foi escolhida em função da sua representatividade no mercado. Por isso, acredita-se que tal estudo será relevante a colaboradores e gestores da empresa, pois estes poderão realizar análises dos indicadores, demonstrando, assim, os pontos fortes e fracos que possam surgir, interna e externamente na organização, envolvendo ainda seu público-alvo e os colaboradores.

\section{RESPONSABILIDADE SOCIAL}

Diante do contexto de grandes desigualdades sociais, problemas políticos e pobreza mundial, por meio da conscientização crescente de indivíduos e grupos da sociedade, nota-se que a responsabilidade social sobre estes efeitos migraram e continuam migrando para as empresas, as organizações e as suas linhas de produção. Conforme Maximiano (2009), devido à deterioração dos ecossistemas, provocada pela poluição e por outros fatores, a responsabilidade social foi estimulada pelo debate sobre os benefícios e malefícios da sociedade industrial.

Mello Neto e Froes (2004) afirmam que este fenômeno está relacionado ao acréscimo do poder dos grupos privados multinacionais. As discussões e as pressões exercidas por parte da sociedade têm como objetivo sensibilizar e conscientizar o empresariado para as questões sociais e ambientais, criando e corroborando maneiras mais harmônicas e solidárias com o interesse da sociedade.

No entendimento de Vidigal, Antunes e Estanqueiro (2000), a responsabilidade social consiste em o indivíduo admitir os seus atos, reconhecendo-se como causador deles, sejam positivos ou negativos. Complementando, Alessio (2008) afirma que a responsabilidade é a possibilidade de prever as consequências do próprio comportamento e corrigi-lo com base nessa previsão.

Para Ashley (2003), a responsabilidade é daquele que é chamado a responder pelos atos frente à sociedade ou à opinião pública. Sob essa ótica, o termo responsabilidade social empresarial significa a obrigação dos empresários de adotar orientações, tomar decisões e seguir linhas de ação que sejam compatíveis com os fins e valores da sociedade.

Pode-se perceber, assim, que não existe até o momento um consenso de definição para responsabilidade social empresarial, podendo representar desde a ideia de obrigação até a ideia de uma contribuição caridosa. Segundo Ashley (2003), hoje em dia as organizações precisam estar atentas não só às suas responsabilidades econômicas e legais, mas também às suas responsabilidades éticas, morais e sociais.

Seguindo o pensamento de Ferrel, Fraedrich, Ferrel (2001), a responsabilidade social no mundo empresarial consiste, fundamentalmente, na obrigação das empresas em elevar ao máximo seu impacto positivo sobre os seus stakeholders (clientes, proprietários, empregados, comunidade, fornecedores e governo) e em minimizar o impacto negativo sobre os mesmos. Os autores acrescentam, ainda, que existem quatro tipos de responsabilidade social: legal, ética, econômica e filantrópica (Figura 1). 
Figura 1 - Tipos de responsabilidade social.

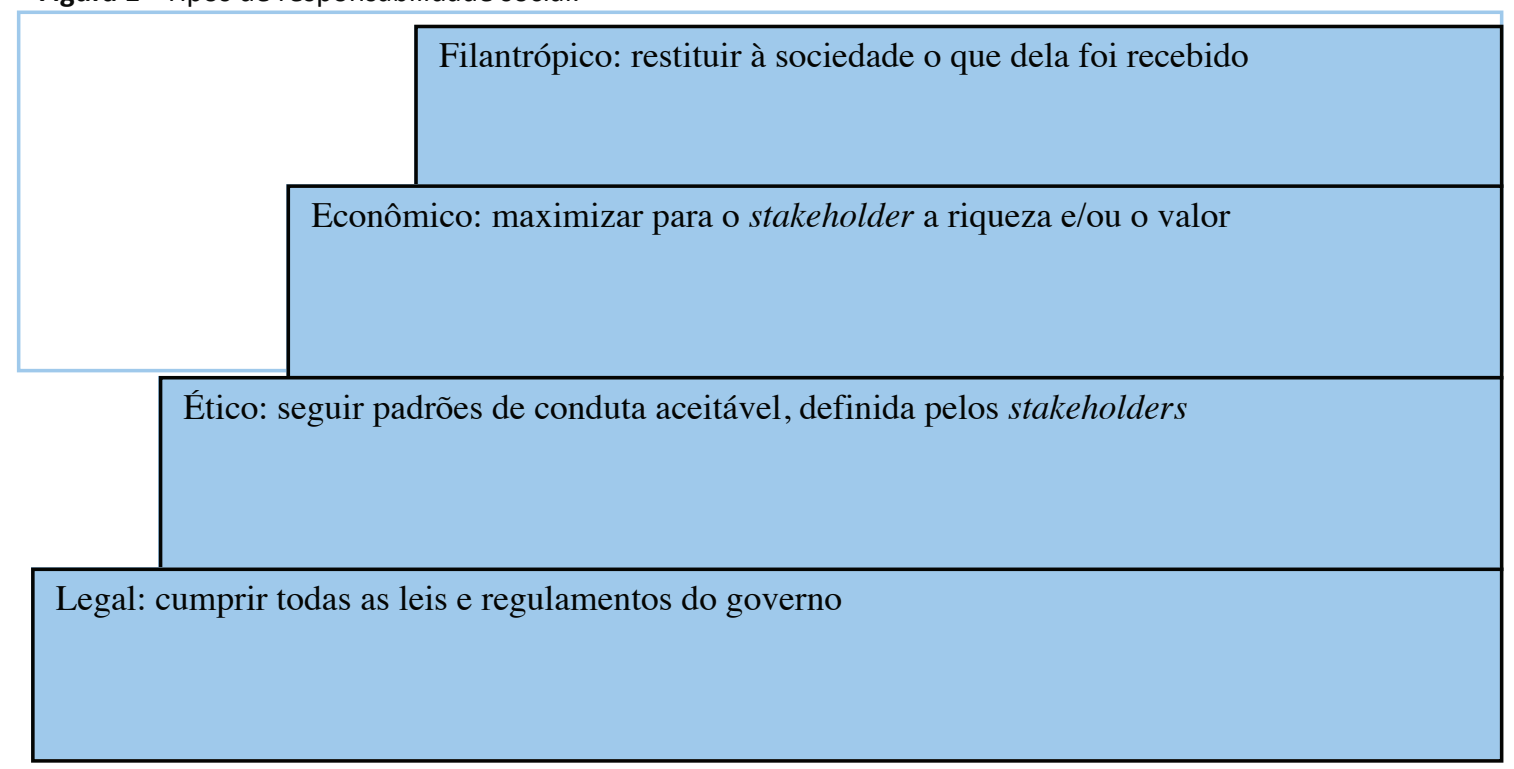

Fonte: Ferrel, Fraedrich e Ferrel (2001, p. 68).

Responsabilidade social empresarial é a uma forma de gestão ética e transparente da empresa em relação a todos os públicos com os quais ela se relaciona. Envolve, também, o estabelecimento de metas empresariais que estimulem o desenvolvimento sustentável da sociedade, preservando os recursos ambientais e culturais para as gerações futuras (INSTITUTO ETHOS, 2003).

Para Karkotli (2006), em uma visão geral, responsabilidade social corporativa é toda e qualquer ação que contribui para a melhoria da qualidade de vida da sociedade, possibilitando, assim, que as organizações demonstrem toda a sua preocupação por meio de projetos sociais.

\subsection{Diretrizes de responsabilidade social empresarial}

As diretrizes de responsabilidade social são ações que têm como objetivo a implementação do desenvolvimento sustentável nas organizações. Conforme Alessio (2008), diretrizes são uma série de ações concretas que podem contribuir para a melhoria da qualidade dos relacionamentos da empresa. Assim sendo, para a implementação da responsabilidade social empresarial, há sete diretrizes: (1) Adote valores e trabalhe com transparência; (2) Valorize empregados e colaboradores; (3) Faça sempre mais pelo meio ambiente; (4) Envolva parceiros e fornecedores; (5) Proteja clientes e fornecedores; (6) Promova sua comunidade; e (7) Comprometa-se com o bem comum (ETHOS, 2003). Na Figura 2, a seguir, identificam-se os aspectos (características) dessas diretrizes.

Figura 2 - Temas e indicadores de responsabilidade social empresarial.

\begin{tabular}{|c|ll|}
\hline Dimensões & & \multicolumn{1}{c|}{ Aspectos (Características) } \\
\hline & $\bullet$ & Governança corporativa; \\
Valores, Trans- & $\bullet$ & Compromissos éticos; \\
parência e Go- & $\bullet$ & Relações com concorrência; \\
vernança & $\bullet$ & Diálogo com stakeholders; \\
& - & Balanço social. \\
\hline
\end{tabular}




\begin{tabular}{|c|c|}
\hline Público Interno & $\begin{array}{ll}\text { - } & \text { Relações com sindicatos; } \\
\text { - } & \text { Relações com trabalhadores terceirizados; } \\
\text { - } & \text { Gestão participativa; } \\
\text { - } \quad \text { Comproção da diversidade; } \\
\text { - } \quad \text { Compromisso com a equidade racial; } \\
\text { - } \quad \text { Compromisso com o futuro das crianças; } \\
\text { - } \quad \text { Compromisso com o desenvolvimento infantil; } \\
\text { - } \quad \text { Comporação para aposentadoria; } \\
\text { - } \quad \text { Compromisso com o desenvolvimento profissional e a empregabilidade; } \\
\text { - } \quad \text { Cuidado com saúde, segurança e condições de trabalho; } \\
\text { Política de remuneração, benefícios e carreira. }\end{array}$ \\
\hline Meio Ambiente & $\begin{array}{l}\text { - } \\
\text { - } \\
\text { Educação e conscientização ambiental; } \\
\text { tos e serviços; } \\
\text { - } \quad \text { Sustentabilidade da economianto florestal; } \\
\text { - } \quad \text { Minimização de entradas e saídas de materiais. }\end{array}$ \\
\hline Fornecedores & $\begin{array}{l}\text { Critérios de seleção e avaliação de fornecedores; } \\
\text { Trabalho infantil na cadeia produtiva; } \\
\text { Trabalho forçado (ou análogo ao escravo) na cadeia produtiva; } \\
\text { Apoio ao desenvolvimento de fornecedores. }\end{array}$ \\
\hline $\begin{array}{c}\text { Consumidores/ } \\
\text { Clientes }\end{array}$ & $\begin{array}{l}\text { Política de comunicação comercial; } \\
\text { Excelência do atendimento; } \\
\text { Conhecimento e gerenciamento dos danos potenciais dos produtos e serviços. }\end{array}$ \\
\hline Comunidade & $\begin{array}{l}\text { Gerenciamento do impacto da empresa na comunidade de entorno; } \\
\text { Relações com organizações locais; } \\
\text { Financiamento da ação social; } \\
\text { Envolvimento com a ação social. }\end{array}$ \\
\hline $\begin{array}{l}\text { Governo e So- } \\
\text { ciedade }\end{array}$ & $\begin{array}{ll}\text { - } & \text { Contribuições para campanhas políticas; } \\
\text { - } & \text { Construção da cidadania pelas empresas; } \\
\text { - } & \text { Práticas anticorrupção e antipropina; } \\
\text { - } \quad \text { Liderança e influência social; } & \text { Participação em projetos sociais governamentais. }\end{array}$ \\
\hline
\end{tabular}

Fonte: Ethos (2003).

Já Mello Neto e Froes (2004, p. 79) destacam um modelo de gestão de responsabilidade social com nove diretrizes (Quadro 1).

Quadro 1 - Modelo de gestão de responsabilidade social.

1. Identificação do escopo de atuação, preferencialmente fora da vizinhança da empresa, ou seja, fora da área de atuação

2. Direcionamento estratégico, privilegiando populações e grupos sociais carentes e priorizando problemas sociais urgentes;

3. Foco na busca de novas oportunidades e alternativas de investimentos sociais;

4. Construção de modelo baseado no uso de novas metodologias;

5. Uso de instrumentos de acompanhamento e avaliação;

6. Forte ênfase na mensuração de retornos obtidos com as ações e os projetos sociais;

7. Estímulo ao uso de parcerias;

8. Estímulo à utilização de soluções inovadoras;

9. Sistema incorporado à cultura empresarial das empresas brasileiras.

Fonte: Mello Neto e Froes (2004).

O desenvolvimento e o gerenciamento destas ações podem ser caracterizados, conforme Mello Neto e Froes (2004), em três estágios:

- o primeiro estágio engloba as atividades regulares da empresa, a saúde e a segurança dos colaboradores e a qualidade do ambiente de trabalho; 
- $\quad$ o segundo estágio refere-se ao ônus das externalidades negativas ao meio ambiente, à sociedade e aos consumidores, incluindo a poluição, o uso de recursos naturais, e a qualidade dos produtos;

- $\quad$ o terceiro estágio abrange questões de bem-estar social, sendo relativo ao momento que a empresa insere-se na sociedade.

Maximiano (2009), por sua vez, caracteriza o que denomina de doutrina da responsabilidade social pelo fato de que as empresas:

- $\quad$ são depositárias de recursos sociais;

- $\quad$ existem com a autorização da sociedade;

- afetam a qualidade de vida da sociedade;

- $\quad$ têm a obrigação de agir segundo os interesses da sociedade;

- $\quad$ devem prestar contas de sua atuação na sociedade.

Nesse sentido, tendo em vista a importância de as empresas aderirem às diretrizes da responsabilidade social para a implementação do desenvolvimento sustentável, o Instituto Ethos, utilizado como referência internacional na área de responsabilidade social, com diretrizes e indicadores próprios, consolida-se como uma organização brasileira sem fins lucrativos, que tem como missão mobilizar, sensibilizar e auxiliar as empresas (micro, pequena, média e grande) a gerirem seus negócios de forma socialmente responsável, tornando as organizações parceiras eficazes e eficientes na construção de uma sociedade justa e sustentável. Portanto, as empresas que se enquadram nas diretrizes que o Instituo Ethos propõe estão assumindo níveis de excelência internacional na área de responsabilidade social.

\subsection{Instituto Ethos}

O instituto Ethos é uma organização sem fins lucrativos, criada em 1998 na cidade de São Paulo, com o intento de promover a interligação das empresas com a sociedade. Define-se como "um polo de organização de conhecimento, troca de experiências e desenvolvimento de ferramentas para auxiliar as empresas a analisar suas práticas de gestão e aprofundar seu compromisso com a responsabilidade social e o desenvolvimento sustentável" (INSTITUTO ETHOS, 2003).

As diretrizes desenvolvidas pelo Instituto são reconhecidas internacionalmente e atuam como a principal referência no Brasil sobre o tema responsabilidade social empresarial. Sua missão é "mobilizar, sensibilizar e ajudar as empresas a gerir seus negócios de forma socialmente responsável, tornando -as parceiras na construção de uma sociedade sustentável e justa" (INSTITUTO ETHOS, 2003).

O Instituto mantém hoje os Indicadores Ethos de responsabilidade social empresarial, incluindo versão para micro e pequenas empresas e também para setores específicos da economia, como o financeiro, o elétrico, o petrolífero e o varejista. Anualmente, realiza a conferência internacional de sustentabilidade e responsabilidade social empresarial (INSTITUTO ETHOS, 2003).

\section{METODOLOGIA}

No que tange aos procedimentos metodológicos, a presente pesquisa possui natureza qualitativa, proporcionando uma melhor compreensão e definição do problema e desenvolvendo uma abordagem. É apropriada ao afrontar uma situação de incerteza em que os resultados 
conclusivos podem, por exemplo, diferir das expectativas (MALHOTRA et al., 2005).

Esta pesquisa caracteriza-se, ainda, como descritiva, tipo que, conforme Rea e Parker (2002), é frequentemente utilizado para extrair informações do entrevistado. Além disso, é preciso levar em conta que parâmetros socioeconômicos, analisados durante a descrição, fornecem informações importantes para melhor entender a população representada pela amostra.

Quanto ao plano de coleta dos dados, o instrumento adotado foi uma entrevista semiestruturada. Conforme Marconi e Lakatos (2010), esse tipo de pesquisa concede liberdade para o entrevistador desenvolver cada situação em qualquer direção que considere adequada. Roesch (1999) complementa que o objetivo da entrevista consiste em entender o significado que os participantes atribuem para a questão em contexto.

A entrevista foi realizada, de forma individual, com sete colaboradores da distribuidora de energia analisada que aceitaram participar do estudo. Destes sete colaboradores, quatro estão localizados na filial e representam $57 \%$ do corpo funcional da amostra e os outros três estão localizados na matriz. Salienta-se que qualquer funcionário poderia participar da pesquisa, independente do seu cargo ou função.

Ressalta-se que o foco deste estudo consistiu no nível operacional da empresa e não no gerencial, uma vez que os funcionários do referido nível são afetados diretamente nas práticas de ações sociais.

\section{ANÁLISE DOS RESULTADOS}

Esta seção contempla as ações sugeridas pelos colaboradores da distribuidora de energia, obtidas por meio da aplicação do roteiro de entrevista semiestruturada.

\section{- Colaborador A - Cargo: Assistente Comercial}

A seguir, no Quadro 2, apresenta-se o resumo das ações sugeridas pelo colaborador A, conforme as dimensões do Instituto Ethos (2003).

Quadro 2 - Ações estratégicas sugeridas pelo entrevistado A.

\begin{tabular}{|l|l|}
\hline \multicolumn{1}{|c|}{ Dimensão } & \multicolumn{1}{c|}{ Ações propostas (respostas) } \\
\hline Valores & $\begin{array}{l}\text { - Divulgação, por meio de palestras e jogos interativos, do Código de Ética e Conduta; } \\
\text { - Fixação de cartazes com os tópicos do código; } \\
\text { - Divulgação via e-mail; } \\
\text { - Dar um livreto. }\end{array}$ \\
\hline Público Interno & $\begin{array}{l}\text { - Elaboração e comunicação do plano de carreira para todos os colaboradores, sejam } \\
\text { estagiários, terceirizados ou primários; } \\
\text { - Incentivar seus colaboradores a estudar, dando bolsas de estudos para todos com } \\
\text { base no critério da frequência escolar; } \\
\text { - Incentivar os colaboradores a participarem de projetos sociais de que a empresa faz } \\
\text { parte. }\end{array}$ \\
\hline Meio Ambiente & $\begin{array}{l}\text { - Aumentar as ações ambientais entre os colaboradores na matriz e na sede; } \\
\text { - Promover a conscientização dos seus colaboradores para adesão ao programa am- } \\
\text { biental. }\end{array}$ \\
\hline Clientes & $\begin{array}{l}\text { - Ressarcir seus clientes caso ocorra algum prejuízo; } \\
\text { - Divulgar as ações voltadas para o público de baixa rendAa, assim como criar constan- } \\
\text { temente novas soluços de acordo com as necessidades; }\end{array}$ \\
\hline Comunidade & - Realizar pesquisas de satisfação do cliente. \\
\hline Governo & $\begin{array}{l}\text { - Utilizar os órgãos públicos e as escolas para difundir conceitos de redução de energia } \\
\text { e comprometer-se com a anticorrupção. }\end{array}$ \\
\hline
\end{tabular}

Fonte: Elaborado pelos autores com base nos dados da pesquisa. 
No resumo de ações sugeridas pelo entrevistado A, apresentado no Quadro 2, percebese que uma das preocupações das ações deste colaborador envolve o desenvolvimento pessoal e profissional, seja do funcionário, do cliente ou da comunidade, como parte integrante do sucesso empresarial.

\section{- $\quad$ Colaborador B - Cargo: Atendente}

Apresenta-se, no Quadro 3, o resumo das ações sugeridas pelo colaborador B, conforme dimensões do Instituto Ethos (2003).

Quadro 3 - Ações estratégicas sugeridas pelo entrevistado B.

\begin{tabular}{|c|l|}
\hline Dimensão & \multicolumn{1}{c|}{ Ações propostas (respostas) } \\
\hline Valores & $\begin{array}{l}\text { - Incluir nas tarefas cotidianas ações que possam trazer à tona os valores da empresa; } \\
\text { - Realizar todo tipo possível de comunicação interna; } \\
\text { - Fazer com que a gerência cobre de seus colaboradores estes atributos. }\end{array}$ \\
\hline Público Interno & $\begin{array}{l}\text { - Avaliar cada funcionário individualmente; } \\
\text { - Aumentar a divulgação dos projetos sociais existentes e incentivar seus colaborado- } \\
\text { res a participarem; } \\
\text { - Aumentar a chance de crescimento para qualquer tipo de funcionário (terceirizado } \\
\text { ou não). }\end{array}$ \\
\hline Meio & $\begin{array}{l}\text { - Aumentar a conscientização dos colaboradores quanto ao uso de recursos naturais } \\
\text { com palestras e panfletos. }\end{array}$ \\
\hline Clientes & $\begin{array}{l}\text { - Fazer um atendimento exclusivo e individual; } \\
\text { - Cumprir os prazos; } \\
\text { - Comunicar os clientes sobre as tarifas especiais. }\end{array}$ \\
\hline Comunidade & - Expor com maior intensidade as propostas da empresa. \\
\hline Governo & - Utilizar meios artísticos (peça teatral) para repassar informações à população. \\
\hline
\end{tabular}

Fonte: Elaborado pelos autores com base nos dados da pesquisa.

Analisando o Quadro 3, identifica-se a importância que o colaborador em questão concede ao atendimento para o cliente, incluindo sua agilidade e exclusividade, bem como ao desenvolvimento profissional dos colaboradores, permeado por tarefas que envolvam os princípios e valores da organização na rotina diária dos colaboradores.

\section{- $\quad$ Colaborador C - Cargo: Estagiário}

A seguir, no Quadro 4, apresenta-se o resumo das ações sugeridas pelo colaborador C, conforme as dimensões do Instituto Ethos (2003).

Quadro 4 - Ações estratégicas sugeridas pelo entrevistado C.

\begin{tabular}{|c|c|}
\hline Dimensão & Ações propostas (respostas) \\
\hline Valores & $\begin{array}{l}\text { - Consultar seus colaboradores para a elaboração do código de ética; } \\
\text { - Garantir que os colaboradores decidam sobre o conteúdo, sem represálias da orga- } \\
\text { nização. }\end{array}$ \\
\hline Público Interno & $\begin{array}{l}\text { - Conceder bolsas estudantis para todos colaboradores de ensino médio, graduação, } \\
\text { pós-graduação e mestrado; } \\
\text { - Garantir a participação proporcional nos lucros da empresa; } \\
\text { - Equiparar salários e benefícios para terceirizados; } \\
\text { - Incentivar os colaboradores a participarem de ações sociais como parte de suas } \\
\text { tarefas diárias. }\end{array}$ \\
\hline $\begin{array}{l}\text { Meio } \\
\text { Ambiente }\end{array}$ & $\begin{array}{l}\text { - Investir constantemente em conscientização e educação; } \\
\text { - Fazer seus colaboradores participarem e se engajarem nas ações ambientais já } \\
\text { existentes. }\end{array}$ \\
\hline
\end{tabular}




\begin{tabular}{|c|l|}
\hline \multirow{2}{*}{ Clientes } & $\begin{array}{l}\text { - Agir com clareza e transparência; } \\
\text { - Ressarci-los caso exista algum dano material; } \\
\text { - Realizar projetos de prevenção de problemas; } \\
\text { - Pensar mais nas pessoas e menos no lucro. }\end{array}$ \\
\hline Comunidade & $\begin{array}{l}\text { - Promover a participação da comunidade na elaboração e execução de projetos vol- } \\
\text { tados a ações ambientais e sociais. }\end{array}$ \\
\hline \multirow{2}{*}{ Governo } & $\begin{array}{l}\text { - Não financiar ou apoiar partidos políticos; } \\
\text { - Incentivar a democracia direta sobre temas fundamentais, tais como a estatização } \\
\text { das empresas de energia elétrica; } \\
\text { - Defender a democratização da liberdade de imprensa. }\end{array}$ \\
\hline
\end{tabular}

Fonte: Elaborado pelos autores com base nos dados da pesquisa

O funcionário $\mathrm{C}$ divulga claramente sua posição em prol dos envolvidos com a organização, seja comunidade, clientes, colaboradores ou meio ambiente. Para o entrevistado, a empresa deve primeiramente olhar para os seus colaboradores e depois pensar no lucro, incentivando a liberdade de expressão e sendo taxativamente contra qualquer tipo de desigualdade ou desconforto no ambiente de trabalho. Cumprir as leis trabalhistas e ambientais é, assim, a obrigação de qualquer organização.

\section{- $\quad$ Colaborador D - Cargo: Técnica em Eletrotécnica}

A seguir, no Quadro 5, consta o resumo das ações sugeridas pelo colaborador $D$, conforme as dimensões do Instituto Ethos (2003).

Quadro 5 - Ações estratégicas sugeridas pelo entrevistado D.

\begin{tabular}{|c|c|}
\hline Dimensão & Ações propostas (respostas) \\
\hline Valores & $\begin{array}{l}\text { - Divulgar seu código de ética através dos meios de comunicação interna; } \\
\text { - Realizar palestras. }\end{array}$ \\
\hline Público Interno & $\begin{array}{l}\text { - Aumentar o número de bolsas estudantis para o ensino médio, a graduação, a } \\
\text { pós-graduação e o mestrado; } \\
\text { - Diminuir o número de terceirizações pelo impacto negativo que acarretam. }\end{array}$ \\
\hline Meio Ambiente & - Realizar campanhas contra o uso excessivo de materiais entre os colaboradores. \\
\hline Clientes & $\begin{array}{l}\text { - Aumentar os canais de comunicação com o cliente; } \\
\text { - Fazer pesquisas de satisfação; } \\
\text { - Realizar projetos de geração de renda e redução no consumo de energia para po- } \\
\text { pulação carente. }\end{array}$ \\
\hline Comunidade & $\begin{array}{l}\text { - Realizar parcerias com prefeituras e associações de bairro para aumentar o grau } \\
\text { de informações entre os interessados. }\end{array}$ \\
\hline & ibuido \\
\hline
\end{tabular}

Dentre as ações indicadas pelo entrevistado $D$, destacam-se a diminuição de empregados terceirizados, a realização de projetos de geração de renda para pessoas carentes e a realização de parcerias com associações de bairro no intuito de facilitar a comunicação da real necessidade dos interessados.

\section{- Colaborador E - Cargo: Engenheiro Eletricista}

O Quadro 6, a seguir, apresenta o resumo das ações sugeridas pelo colaborador E, conforme as dimensões do Instituto Ethos (2003).

Quadro 6 - Ações estratégicas sugeridas pelo entrevistado E.

\begin{tabular}{|c|l|}
\hline Dimensão & \multicolumn{1}{c|}{ Ações propostas (respostas) } \\
\hline Valores & - Divulgar seu Código de Ética através dos meios de comunicação interna. \\
\hline Público Interno & - Aumentar o número de incentivos (benefícios culturais e intelectuais). \\
\hline
\end{tabular}




\begin{tabular}{|c|l|}
\hline $\begin{array}{c}\text { Meio } \\
\text { Ambiente }\end{array}$ & - Realizar programas de conscientização de colaboradores. \\
\hline Clientes & - Cumprir a legislação brasileira rigorosamente. \\
\hline Comunidade & - Envolver-se em ações sociais. \\
\hline Governo & - Divulgar os valores e princípios da distribuidora de energia para toda a população. \\
\hline
\end{tabular}

Fonte: Elaborado pelos autores com base nos dados da pesquisa

De acordo com o entrevistado $E$, destacam-se ações comunicativas e de conscientização entre os colaboradores. É possível, neste caso, identificar uma não preocupação com os aspectos que envolvem o tema deste trabalho e certo "comodismo" quanto à realização apenas daquilo que determina a legislação brasileira.

\section{- $\quad$ Colaborador F - Cargo: Analista de Negócios}

A seguir, no Quadro 7, consta o resumo das ações sugeridas pelo colaborador " $F$ ", conforme as dimensões do Instituto Ethos (2003).

Quadro 7 - Ações estratégicas sugeridas pelo entrevistado F.

\begin{tabular}{|c|l|}
\hline Dimensão & \multicolumn{1}{c|}{ Ações propostas (respostas) } \\
\hline Valores & $\begin{array}{l}\text { - Distribuir o seu código de ética e conduta; } \\
\text { - Realizar reuniões e seminários com a participação efetiva dos colaboradores para } \\
\text { esclarecimentos de dúvidas. }\end{array}$ \\
\hline Público Interno & $\begin{array}{l}\text { - Conceder bolsas estudantis para todos os colaboradores do ensino médio, da gra- } \\
\text { duação, da pós-graduação e do mestrado; } \\
\text { - Instituir quadro de carreira; } \\
\text { - Incentivar colaboradores terceirizados; } \\
\text { - Divulgar projetos ambientais pela intranet e por meio de murais. }\end{array}$ \\
\hline Meio Ambiente & - Realizar campanhas regulares de conscientização para eliminar desperdícios. \\
\hline Clientes & $\begin{array}{l}\text { - Agir de forma preventiva; } \\
\text { - Providenciar o reembolso de prejuízos; } \\
\text { - Proceder conforme a legislação; } \\
\text { - Cumprir os prazos estabelecidos na legislação. }\end{array}$ \\
\hline Comunidade & $\begin{array}{l}\text { - Impulsionar eventos que percorrem a cidade, como a caravana da distribuidora de } \\
\text { energia. }\end{array}$ \\
\hline Governo & $\begin{array}{l}\text { - Promover eventos com especialistas, cientistas sociais políticos e representantes } \\
\text { do poder público para discutir assuntos como ética e cidadania. }\end{array}$ \\
\hline
\end{tabular}

Fonte: Elaborado pelos autores com base nos dados da pesquisa

Verifica-se que as ações mencionadas pelo colaborador $\mathrm{F}$ denotam a preocupação em conscientizar, por meio da educação, todos que, de alguma forma, participam ou se envolvem com a distribuidora de energia. Analisando as ações sugeridas pelos entrevistados A, B, C, D, E e F, percebe-se que estes reivindicam ações semelhantes, principalmente quanto ao público interno.

\section{- $\quad$ Colaborador G - Cargo: Administrador de Empresas}

Apresenta-se, no Quadro 8, o resumo das ações sugeridas pelo colaborador $\mathrm{G}$ conforme as dimensões do Instituto Ethos (2003).

Quadro 8 - Ações estratégicas sugeridas pelo entrevistado G.

\begin{tabular}{|c|l|}
\hline Dimensão & \multicolumn{1}{c|}{ Ações propostas (respostas) } \\
\hline Valores & $\begin{array}{l}\text { - Distribuir o seu código de ética e conduta; } \\
\text { - Realizar reuniões, seminários e palestras. }\end{array}$ \\
\hline
\end{tabular}




\begin{tabular}{|c|l|}
\hline & $\begin{array}{l}\text { - Realizar cursos de atualização e aperfeiçoamento profissional; } \\
\text { - Valorizar o quadro de carreira, levando em conta as características pessoais de } \\
\text { cada funcionário; }\end{array}$ \\
- Criar eventos internos para troca de conhecimentos, leituras e palestras temáticas \\
com doutores e artistas; \\
- Incentivar colaboradores terceirizados; \\
- Equiparar benefícios para os terceirizados.
\end{tabular}

Fonte: Elaborado pelos autores com base nos dados da pesquisa

Percebe-se que as ações sugeridas pelo entrevistado $\mathrm{G}$ se relacionam e assemelham com os resultados da matriz SWOT também realizada na empresa - uma sigla em inglês que significa Strengths (Forças), Weaknesses (Fraquezas), Opportunities (Oportunidades) e Threats (Ameaças) - explicam Gonçalves et al. (2010), tendo em vista a inclusão de aspectos como realizar campanhas internas de precaução e conscientização, cumprir prazos e agir conforme a legislação. Em sua concepção, a organização deve dar mais atenção às habilidades individuais de cada funcionário, promovendo e incentivando o conhecimento via livros, escolas e universidades.

\subsection{Identificação das sugestões de melhorias}

Neste item, baseado nas entrevistas realizadas com os colaboradores da distribuidora, sugestões para uma maior amplitude da responsabilidade social foram elaboradas. Essas sugestões se baseiam no aprofundamento das ações sociais e na compreensão de que a organização tem o dever de assumir o papel de agente de melhoria social, por meio da preocupação com o meio ambiente e com a sociedade, e melhoria da qualidade de vida de seus colaboradores.

Diante disso, são apresentadas, no Quadro 9, as principais sugestões de melhorias apontadas pelos colaboradores no momento da entrevista.

Quadro 9 - Sugestões de melhoria propostas pelos entrevistados.

\begin{tabular}{|c|ll|}
\hline Dimensão & Sugestões de melhoria \\
\hline Valores & $\bullet \quad \begin{array}{l}\text { Palestras bimestrais abertas ao público; } \\
\text { Reuniões e seminários para os colaboradores; } \\
\text { Inclusão dos valores e princípios na rotina/tarefas dos colaboradores; } \\
\text { Elaboração do código de ética em conjunto com colaboradores; } \\
\text { Distribuição do código de ética. }\end{array}$ \\
\hline
\end{tabular}




\begin{tabular}{|c|c|}
\hline Público Interno & $\begin{array}{l}\text { - } \quad \text { Conceder bolsas escolares para ensino médio, técnico, superior, pós-gra- } \\
\text { duação, mestrado e doutorado para todos os colaboradores; } \\
\text { - } \quad \text { Promover a participação nos lucros; } \\
\text { - } \quad \text { Dar auxílios: creche, farmácia, transporte estudantil e funeral; } \\
\text { - } \quad \text { Diminuir terceirizados; } \\
\text { - } \quad \text { Criar plano de carreira; } \\
\text { - } \quad \text { Extinguir as desigualdades entre colaboradores e terceirizados; } \\
\text { - } \quad \text { Estinguir o banco de horas; } \\
\text { - } \quad \text { Incentivar seus colaboradores a promoverem e participarem de ações sociais. }\end{array}$ \\
\hline Meio Ambiente & $\begin{array}{l}\text { - Conscientizar colaboradores com palestras sobre os impactos que a distri- } \\
\text { buidora de energia ocasiona; } \\
\text { - } \quad \text { Elaborar programa educacional para colaboradores e público em geral; } \\
\text { - } \quad \text { Difundir (expandir) os programas existentes de eficiência energética; } \\
\text { - Incentivar programas de desenvolvimento e inovação. }\end{array}$ \\
\hline Clientes & 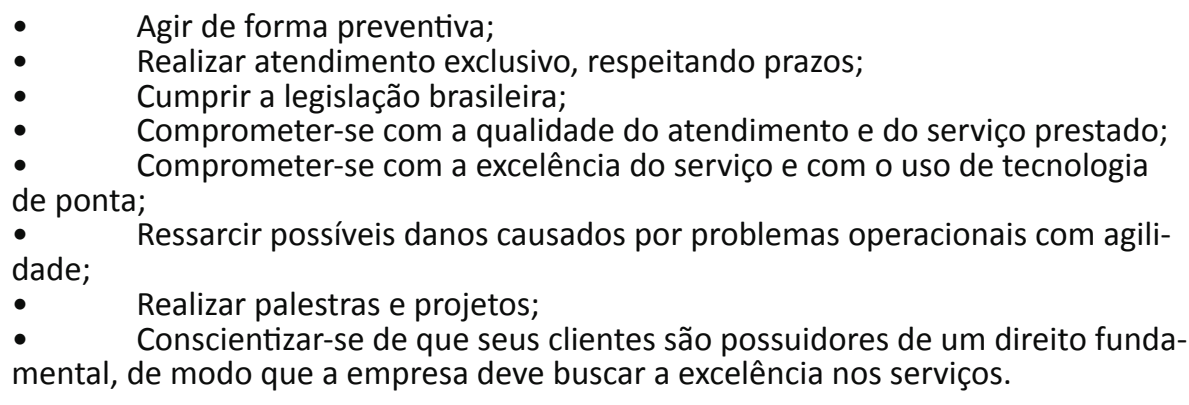 \\
\hline Comunidade & $\begin{array}{l}\text { - } \quad \text { Expor suas propostas; } \\
\text { - } \quad \text { Realizar projetos e palestras; } \\
\text { - } \quad \text { Promover a participação da comunidade em ações de cidadania e meio } \\
\text { ambiente; } \\
\text { - Criar parcerias com associações de bairros. }\end{array}$ \\
\hline Governo & $\begin{array}{l}\text { - } \quad \text { Elaborar projetos educativos para a rede de escolas públicas; } \\
\text { - } \quad \text { Desenvolver parcerias com o governo; } \\
\text { - Utilizar o programa de eficiência elétrica em todas as esferas públicas (es- } \\
\text { colas, hospitais, praças, postes de luz, secretarias e ministérios do governo). }\end{array}$ \\
\hline
\end{tabular}

Fonte: Elaborado pelos autores com base nos dados da pesquisa

A adoção das ações sugeridas no Quadro 9 refletiria uma mudança na forma de agir da empresa, bem como impactaria significativamente a vida de seus colaboradores. É preciso levar em consideração a importância de novas e duradouras ações em prol do meio ambiente e da humanidade.

Nesse sentido, a partir da aplicação desse plano de melhorias, a empresa estaria aperfeiçoando cada vez mais em seus princípios e valores, podendo atingir, assim, o status de referência brasileira para o setor elétrico em termos de responsabilidade social, cidadania e valores humanos.

De acordo com as sugestões de melhorias apontadas pelos colaboradores, foram selecionadas algumas ações por dimensão para a elaboração de um plano de melhorias, o qual se encontra no Quadro 10. 
Quadro 10 - Ações estratégicas selecionadas

\begin{tabular}{|c|c|}
\hline Dimensão & Sugestões de melhoria \\
\hline $\begin{array}{l}\text { Público } \\
\text { Interno }\end{array}$ & $\begin{array}{l}\text { - Conceder bolsas escolares para ensino médio, técnico, superior, pós-gradua- } \\
\text { ção, mestrado e doutorado para todos os colaboradores; } \\
\text { - } \quad \text { Promover participação nos lucros; } \\
\text { - } \quad \text { Conceder auxílios e benefícios (creche, farmácia, transporte estudantil, fu- } \\
\text { neral, prêmio assiduidade, programa de aposentadoria e } \\
\text { bônus energia); } \\
\text { - } \quad \text { Criar plano de carreira; } \\
\text { - } \quad \text { Extinguir as desigualdades entre colaboradores e terceirizados; } \\
\text { - } \quad \text { Extinguir o banco de horas; } \\
\text { - }\end{array}$ \\
\hline Clientes & $\begin{array}{l}\text { - } \quad \text { Realizar atendimento exclusivo e individual, respeitando prazos; } \\
\text { Ressarcir possíveis danos causados por problemas operacionais com agilidade. }\end{array}$ \\
\hline $\begin{array}{c}\text { Meio } \\
\text { Ambiente }\end{array}$ & $\begin{array}{l}\text { Elaborar programa educacional ambiental para colaboradores e público em } \\
\text { geral, englobando principais impactos causados pela empresa e capacitando colabo- } \\
\text { radores para serem agentes ambientais em cada unidade da distribuidora; } \\
\text { - } \quad \text { Aumentar incentivos para o programa de redução do impacto ambiental; } \\
\text { - } \quad \text { Elaborar comissão de planejamento e inovação para energia sustentável. }\end{array}$ \\
\hline Valores & $\begin{array}{l}\text { - } \quad \text { Realizar reuniões e seminários para os colaboradores e o público em geral; } \\
\text { - } \quad \text { Incluir os valores e princípios na rotina/tarefas dos colaboradores; } \\
\text { - Elaborar código de ética em conjunto com os colaboradores e distribui-lo } \\
\text { aos envolvidos. }\end{array}$ \\
\hline Comunidade & $\begin{array}{ll}\text { biente; } & \text { Promover a participação da comunidade em ações de cidadania e meio am- } \\
\bullet & \text { Realizar parcerias com associações de bairros. }\end{array}$ \\
\hline Governo & $\begin{array}{l}\text { Elaborar projetos educativos para a rede de escolas públicas; } \\
\text { - } \quad \text { Uesenvolver parcerias com o governo; } \\
\text { - } \quad \text { Utilizar o programa de eficiência elétrica em todas as esferas públicas (esco- } \\
\text { las, hospitais, praças, postes de luz, secretarias e ministérios do governo). }\end{array}$ \\
\hline
\end{tabular}

Fonte: Elaborado pelos autores com base nos dados da pesquisa

Diante de tais resultados, tendo em vista o aprofundamento das ações sociais e o fato de que a organização tem o dever de assumir o papel de agente de melhoria social (via preocupação com o meio ambiente e com o desenvolvimento da sociedade) e de melhoria da qualidade de vida de seus funcionários, acredita-se que este estudo contribuiu para uma maior amplitude da responsabilidade social da distribuidora aqui analisada.

\section{CONSIDERAÇÕES FINAIS}

Partindo do objetivo deste estudo, que consiste em propor ações de melhoria no Programa de Responsabilidade Social, com base no Instituto Ethos, em uma distribuidora de energia elétrica, é possível afirmar que os resultados encontrados indicam uma predominância de convergência nas respostas dos colaboradores, ou seja, respostas similares que orientam para a mesma solução. Percebe-se, assim, que os colaboradores têm consciência do papel que a empresa de energia elétrica vem desenvolvendo na busca contínua da qualidade, demonstrando informalmente certo grau de satisfação em relação à organização.

Constata-se, ainda, que as respostas dos entrevistados se baseiam em reivindicações para a melhoria do ambiente de trabalho e da qualidade de vida, evidenciando seu desejo de que suas reivindicações se realizem na forma de projetos e ações. Todavia, questionados sobre o que pensavam acerca do programa de responsabilidade social da empresa, se apenas é uma estraté- 
gia de negócios ou se faz parte dos princípios da empresa, a maioria dos entrevistados acredita que esse programa constitui parte dos valores, dos princípios e da missão da organização.

Diante disso, ressalta-se, por fim, como limitação deste estudo, embora o objetivo proposto tenha sido alcançado, o fato de ter sido realizado em apenas uma empresa. Assim, como sugestão para pesquisas futuras, visando contribuir com novas discussões sobre o tema, recomenda-se replicar este estudo em outras organizações de diferentes segmentos, bem como em outras distribuidoras do país a fim de comparar os resultados aqui obtidos.

\section{REFERÊNCIAS}

ALESSIO, R. Responsabilidade social das empresas no Brasil: reprodução de postura ou novos rumos? Porto Alegre: Edipucrs, 2008.

ASHLEY, P. A. Ética e responsabilidade social nos negócios. São Paulo: Saraiva, 2003.

FERREL, O. C.; FRAEDRICH, J.; FERREL, L. Ética empresarial: dilemas, tomadas de decisões e casos. São Paulo: Reichmann \& Affonso, 2001.

GONÇALVES, L. R. G.; CINTRA, G. B.; TEIDER, B. H.; GALLO, J. B.; PANDOLFELLI, V. C. Aplicação da ferramenta SWOT para avaliação das técnicas de dano ao choque térmico em materiais refratários. Cerâmica, São Paulo, v. 56, n. 340, p. 320-324, 2010.

INSTITUTO ETHOS. Práticas empresariais de responsabilidade social: relação entre os princípios do Global Compact e os Indicadores Ethos de Responsabilidade Social Empresarial. São Paulo: Instituto Ethos, 2003.

KARKOTLI, G. Responsabilidade social empresarial. Petrópolis: Vozes, 2006.

MALHOTRA, N. K. et al. Introdução à pesquisa de marketing. São Paulo: Person Prentice Hall, 2005.

MARCONI, M. de A.; LAKATOS, E. M. Fundamentos de metodologia científica. 7. ed. São Paulo: Atlas, 2010.

MAXIMIANO, A. C. A. Teoria geral da administração: da escola científica à competitividade em economia globalizada. 6 . ed. São Paulo: Atlas, 2009.
MELLO NETO, F. P. de; FROES, C. Gestão da responsabilidade social corporativa: o caso brasileiro: da filantropia tradicional à filantropia de alto rendimento e ao empreendedorismo social. Rio de Janeiro: Qualitymark, 2004.

REA, L. M.; PARKER, R. A. Metodologia de pesquisa: do planejamento a execução. São Paulo: Pioneira, 2002.

ROESCH, S. M. A. Projetos de estágio e de pesquisa em administração: guia para estágios, trabalho de conclusão, dissertações e estudo de casos. São Paulo: Atlas, 1999.

VIDIGAL, M.; ANTUNES, A.; ESTANQUEIRO, A. Dicionário breve de filosofia. Portugal: Presença, 2000. 